\title{
DISSEMINATED SCLEROSIS
}

\author{
BY
}

\author{
MICHAEL KREMER, M.D., B.Sc., F.R.C.P. \\ Physician, Department of Nervous Diseases, Middlesex Hospital ; \\ Physician, National Hospital, Queen Square, London
}

It is still unfortunately true that there is no specific remedy in disseminated sclerosis, but it would be very wrong indeed for this reason to abandon these patients without treatment of any kind, for much can be done to give symptomatic relief. As important as anything else in the treatment of this condition is the attitude of the doctor. There is still some ignorance in the profession of the natural history of the disorder, and once the diagnosis is made a feeling of pessimism may overwhelm the practitioner, who feels he is faced with a hopeless patient soon to be reduced to a life of chronic incapacity and needing almost full-time care. That this is not the case is by no means sufficiently widely known.

The frequency of the disease in Great Britain is about one in 2,000 of the population; it varies in different counties. There are therefore a large number of sufferers, and it is clear at once that there are not that number of severely incapacitated patients in this country suffering from disseminated sclerosis. Many of these patients have long periods of remission often lasting many years. There are others whose disorder is mild, and, while they may have many abnormal signs in the nervous system, yet disorder of function and impairment of useful life are slight.

An explanation to the intelligent patient along these lines may be very helpful ; it may prevent him from feeling that the doctors are abandoning him and stop him and his relations from wandering round seeking help which is not available.

\section{Lines of Attack}

Many treatments of the disease have been tried, but assessment of results is impossible except on a very longterm basis, as any therapy may coincide with a natural remission. The major lines of attack are as follows.

Vaccines.-The latest of these is the Shubladze-Margulis vaccine from the U.S.S.R. There is no evidence yet available that this has any effect on the disease and it is possible that the substance is dangerous. Bacterial vaccines, usually autogenous, have been tried, and these too have not been accepted as producing any relief.

Pyrexia.-Before the second world war there was a great vogue for pyrexial treatment. The pyrexia was induced by the use of killed organisms, such as T.A.B. vaccine, intravenously, and the patient was allowed to have up to six or even more bouts of fever. But in recent years this method of treatment has been used less and less. There is no doubt that it could initiate a remission for a time.

Vasodilators.-This is a useful method of treatment and may be of considerable help in bringing a relapse to an end rather sooner than would otherwise happen. Probably any vasodilator would be effective, but many have unpleasant side-effects. The least unpleasant is nicotinic acid given in flushing doses. This may be 50-100 mg. given three times daily before meals. The patient must be warned that in 15-30 minutes a feeling of flushing, paraesthesiae, unpleasant fullness in the head, and an odd taste will be produced. These symptoms rarely last more than 15-20 minutes. If no great flush is produced when the nicotinic acid is taken by mouth, it may be given in doses of 50-100 mg. either intravenously or intramuscularly once daily. It is useful to continue this treatment for four to six weeks and then to discontinue it for about the same period before starting again. Nicctinic-acid derivatives which do not produce vasodilatation are not so beneficial.

Histamine in rising dosage has also been given, but it causes headache and perhaps is not so easy to control. If it is used, then a starting dose such as $0.1 \mathrm{mg}$. intravenously begins the course, and it can be increased by $0.1 \mathrm{mg}$. daily or even twice daily.

Steroids.-Like vasodilators, steroids may be very helpful in initiating a remission, but if no obvious effect is being produced within two or three weeks then they should be tailed off fairly quickly; but, if benefit is obtained, the steroids may be continued for two or three months. The usual careful watch for toxic results must be maintained. A good starting dose is $10 \mathrm{mg}$. of prednisone three times a day, and it may usefully be combined with nicotinic acid. A.C.T.H. in doses of 50 units daily by injection has also been prescribed for three or four weeks and then gradually reduced to a maintenance dose of $\mathbf{1 0}$ units daily for several months. The good effects are unfortunately transient.

Arsenic.-The vogue of arsenic therapy seems to have diminished recently, though there are many neurologists who still use it quite extensively. The usual mode of administration is to combine both organic and inorganic arsenic. In each course neoarsphenamine is given intravenously once a week in doses of $0.15 \mathrm{~g}$., $0.3 \mathrm{~g}$., $0.45 \mathrm{~g}$., and $0.45 \mathrm{~g}$. This four-weeks course can be repeated every three to four months. If the veins are difficult to enter, then intramuscular sulpharsphenamine in corresponding doses is given. Between injections liq. arsenicalis, 3-5 minims $(0.2-$ $0.3 \mathrm{ml}$.), is given for three weeks each month. Careful watch must be kept for intolerance to arsenic.

Intrathecal Treatment.-It has been suggested at Oxford that P.P.D. (purified protein derivative of tuherculin) given intrathecally produces a specific response in the cerebrospinal fluid of Mantoux-positive patients and that there may also be a helpful therapeutic effect. It is too early to assess the merits of this procedure, which can be carried out only in hospital.

Whichever of these means of treatment is used, if the patient's mobility is affected, whether owing to disturbance of power, tone, co-ordination, or sensation, then re-education with the help of trained physiotherapists is an essential part of treatment. It is probable that at present this may well be the most important part of treatment. and it is clear that this calls for special training of physiotherapists and for their being part of a team engaged specially in helping such disorders of mobility and equilibrium. Unless the therapists know what they are trying to achieve and have adequate leadership, they may well share the hopelessness that is so frequently seen in those faced with these patients. It is remarkable how much an enthusiastic doctor or department can achieve in restoring really useful function, quite apart from the help that can be given by introducing mechanical aids in the kitchen, bathroom, and elsewhere in the house.

\section{Symptomatic Treatment}

In addition to treating the patient as a whole, some symptomatic treatment can give help.

Hypertonus and Spasms.-Occasionally hypertonicity is so great, especially in the hip adductors and plantar flexors, 
that even with reasonable power walking is difficult. Some patients gain relief from meprobamate or mephenesin. The former can be started in 200-mg. doses three times a day after meals and the latter as mephenesin carbamate in 0.5-g. doses three times a day. Each can be pushed up to double or even treble these doses, provided the patient does not become too drowsy and there is no gastric irritation.

Extensor and flexor spasms may be very troublesomedisturbing rest and posture, and often being associated with a good deal of pain. Both meprobamate and mephenesin may help to diminish these contractions, but often so large a dose is necessary that the patient may be asleep the greater part of the day. In such a case it is probably better to give smaller doses such as $400 \mathrm{mg}$. of meprobamate three or four times a day and add small quantities of barbiturate such as phenobarbitone $\frac{1}{2}$ gr. $(32 \mathrm{mg}$.) or amylobarbitone $\frac{1}{2}$ gr. ( $32 \mathrm{mg}$.) to each dose.

Unfortunately there are many advanced cases in which no drug treatment has any effect on the spasms, and life is rendered almost intolerable by the continuous violent and painful contractions. In such patients the only reasonable treatment is selective surgical section of peripheral nerves or fractional knock-out of spinal anterior nerve roots by means of phenol. Both these techniques require expert performance by someone familiar with the hazards of the procedures, but offer the possibility of turning an impossible existence into a more comfortable though paraplegic life.

Vertigo.-This symptom, with associated disequilibrium and vomiting, is usually due to a brain-stem plaque damaging the central connexion from the vestibular labyrinths. The treatment is the same as that of any acute vertigo. While vomiting is going on the intramuscular injection of $50 \mathrm{mg}$. of promethazine, chlorpromazine, or promazine will often ease the acute disturbance. If the attack is very severe the injection may have to be repeated some six hours later. The drowsiness which results is welcomed by the patient. Once the acute vomiting has ceased, then the same substances can be given by mouth in $25-\mathrm{mg}$. doses two or three times a day, or prochlorperazine ("stemetil ") in doses of 5-10 mg. twice a day can be substituted. This drug produces less drowsiness.

Sphincter Disturbances. - The function of the bladder is commonly disturbed and the patient suffers from frequency, urgency, and precipitancy of micturition. Later incontinence may occur, but this is often due to a combination of precipitancy with diminished mobility. Retention is unusual except in the acute paraplegias due to a transverse plaque.

It is difficult to control the rapidly emptying spastic bladder except by sedation, but occasionally the use of a pill containing ergot 1 gr. $(65 \mathrm{mg}$.) and ext. belladonnae sicc. $\frac{1}{4}$ gr. (16 mg.) may be helpful. Frequently, however, and especially in women, the urinary disturbance is accentuated by infection. If there is any real risk of this it may be helpful to keep the patient on small doses of sulphonamide such as sulphathiazole $0.5 \mathrm{~g}$. twice a day, or sulphamethizole ("urolucosil") 0.2 g. twice a day for some months. If an obvious acute infection supervenes, then treatment with the specific substance to which the organism is sensitive is clearly indicated. Several courses may have to be given before the urine becomes sterile. Occasionally the longcontinued use of sulphonamides may be interrupted with a course of hexamine mandelate, $0.5 \mathrm{~g}$. three times a day for two or three weeks.

Retention of urine is treated by administering the stable esters of acetylcholine, of which there are many preparations available, in doses of $0.25 \mathrm{mg}$. intramuscularly or $1 \mathrm{mg}$. by mouth, repeated if need be. When this fails catheterization will be necessary.

The bowel difficulty is usually constipation, and diarrhoea and rectal urgency are most often the result of incautious aperients. It is safer to give only mild laxatives and supplement these by glycerin suppositories or "dulcolax" (2-(4:4'-diacetoxydiphenylmethyl) pyridine) suppositories.
Enemas may be necessary, but it is essential to avoid irritating the bowel either from above or from below.

Pain.-This is a fairly frequent symptom in this disease. The pain may be associated with muscle spasms as already described, but other forms are as follows:

(a) Lightning pains.

(b) Root pain indistinguishable from a brachial neuralgia or sciatica or a trigemınal neuralgia.

(c) Headache due to plaques causing narrowing of the aqueduct of Sylvius and oedema, or interfering with the root entry zones of sensory nerves.

(d) Central pains due to involvement of the spinothalamic tract or the thalamus. Here the pain is of an intense burning and gnawing character, often with a profound affective reaction.

(e) Painful paraesthesiae.

The treatment of all forms of pain in this condition is to use the analgesics such as compounds of aspirin, phenacetin, and codeine in full doses unless gastric irritation and constipation are troublesome. Their efficiency is often greatly enhanced by adding small quantities of sedative such as amylobarbitone in doses of $\frac{1}{2}-1 \mathrm{gr}$. (32-65 mg.), and during the earlier part of the day by adding also an analeptic such as dexamphetamine $5 \mathrm{mg}$. This is particularly helpful for central pain and painful paraesthesiae.

Pressure Sores.-Once the patient is confined to a chair or bed the risk of pressure sores is great. This is particularly so if there is sensory impairment and urinary overflow.

They can be avoided only by scrupulous attention to the nursing care of the skin at the points of pressure, by changes of posture, and by the use of smooth bed linen or special seats. There is no drug which will help more than the efficient use of soap, spirit, and occasiona ly a silicone skin cream. The healing of pressure sores is so slow and the risk of spread in the paraplegic so great that treatment must be preventive. Once pressure sores are present, the only really effective treatment is prevention of weight bearing by the sore area. Necrotic tissue must be removed, and antiseptic creams may help to some extent.

\section{Morale}

It must be clear now that a great deal can be done for these patients to provide some symptomatic relief, but it is equally clear that the essential part of treatment is the maintenance of morale in the patient and the relatives at as high a level as is possible. Patients can be helped by using all the benefits provided by the Health Service, in particular the provision of wheel-chairs, perhaps even motorized chairs, commodes, gadgets, and other appliances, but the most essential contribution to keeping up morale is the attitude of the medical staff of every kind who come into contact with the patient.

Reporting on legal proceedings taken in 1957, the City Analyst for Birmingham writes in his Annual Report: "Only twice was it necessary to use the 'big stick' of prosecution, and on both occasions farmers were the culprits; the use of this weapon against food and drug retailers has to all intents and purposes been abandoned. A very different picture is presented in the first annual report made by me as city analyst in 1929; in that year 12 farmers were prosecuted in respect of 49 samples, and fines were imposed in 45 cases. Two of these farmers were each fined $£ 100$ for adulteration on the grand scale, which it was calculated resulted in both cases in the sale of 100 gallons of water per week as milk. In addition, summonses were issued in respect of four.other foods and drugs. The total fines paid by offenders amounted to $£ 328$ : this figure is practically ten times as great as the corresponding one for 1957 , and this reduction of $90 \%$ is an indication both of a greater sense of responsibility on the part of manufacturers and of a changed attitude on the part of local authorities." 